\title{
Effect of Games on University Sports Teaching and Problems while Application
}

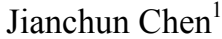 \\ ${ }^{1}$ Qingdao University of Science and Technology, Qingdao, China \\ Correspondence: Jianchun Chen, Qingdao University of Science and Technology, Qingdao 266061, China. \\ E-mail: baijuan@qust.edu.cn
}

Received: June 3, 2013 Accepted: June 18, 2013 Online Published: June 29, 2013

doi:10.5539/ass.v9n9p257 URL: http://dx.doi.org/10.5539/ass.v9n9p257

\begin{abstract}
It is widely acknowledged that university sports are both essential and beneficial to the youth's physical and mental growth, while sport games play an important role in the application of university sports teaching. This paper summarizes the characteristics of sports games and the functions of sports games in university sports teaching. And then, combining with actual teaching experience of the author, the paper explores the problems appearing during sports teaching. This paper will contribute to improving fun of teaching and strengthening constitution of the students.
\end{abstract}

Keywords: sports games, university sports, sports teaching

\section{Introduction}

As the deepening reform of university quality-oriented education in our country, to improve students' physical fitness and strengthen their constitution comprehensively has become a serious problem emphasized by the whole society, universities and their parents. Modern university students have higher standards towards health and interest of sports activities. Thus, sports games are paid increasing attention for their good physique effect and strong interest. The effect of adding sports games into university sports teaching is obvious ${ }^{[1]}$. So construction of sports games in university sports teaching shall be enhanced and sports games should be applied into practical teaching reasonably considering their functions and problems needed to be paid.

\section{Sports Games}

Sports games are characterized by their interestingness, popularity, competitiveness, entertainment, intelligence, knowledge, and so on. Popularity, learnability and using local materials of sports games provide rich teaching methods and measures for university sports teaching, a special way. So in this way, students will not feel bored or tired, which is also correspond to mental and physical features of modern university students. That's why sports games are popular with university students. Content of sports games is wide. All items of sports can be taken as content of sports games. Their special ways and fit-keeping effect cannot be reached by other items. Furthermore, they are not limited by field and instruments, which are so simple that they are easy to be popularized and developed.

At the same time, sports games have certain plot and competition factors and there are thoughts, life and directness in them with lovely and vivid forms which are one of interested activities for students. If characteristics above are lost, it will become boring, which not only cannot reach the effect, but also reduce activity of the students and lose the meaning. Thus, it is an important supplementary means, which is favorable for developing and of students' physical strength, intelligence, behaviors and some nonintellectual factors, which play an important role in sports teaching.

\section{Functions of Sports Games}

\subsection{Education Function of Sports Games}

Different arrangement and contents of the games can develop people's volitional qualities and embody their spirit of being brave to struggle and to face difficulties and to deal with the difficulties actively. At the same time, it can also cultivate the communist ideology and morality and sentiment. Games can help students understand right and wrong, victory and defeat in life, which can cultivate the communist ideology and morality and 
sentiment. For example, carrying out the rules and following the judgment while doing sports games, are favorable for students to form behavioral habit to observe disciplines and obey laws. At the same time, games enable students develop collective spirit of unity and cooperation and understand the relationship between unity and individuals in a right way. Moreover, as sports games has competitiveness and they have good settings in activity density and quantity, they are suitable for students to take part in and they can make their bodies strengthen, improve their sports skills and physical fitness, and teach students how to do exercises in scientific and reasonable way. For example, basketball games of "chasing and laying up" can not only practice students' skill of laying up, but also increase interestingness, which help students willing to practice basketball skills actively and to practice for sense of group honor.

\subsection{Function of Provoking Thinking and Promoting Development of Intelligent and Non-intelligent Factors}

Sports games are a kind of complex conditioned reflex process, which can improve the analysis ability of the cerebral cortex to the interoceptor and the exteroceptor. So in sports games, creativity, cognition, receptivity and other abilities can be developed and practiced, by which problem-solving ability is enhanced, so that intelligence is developed. Vivid forms of sports game teaching integrate interest, ability and practice as a whole, with the characteristics of interest, thrill, competition, knowledge and intelligence that the class is full of vitality, so that potential of students can be fully developed, collective consciousness is enhanced and competitive spirit is improved. In that way, the students can not only experience interests of sports teaching, but also improve their physical fitness and then non-intelligent factors, like consciousness, decisiveness, initiative and braveness can be developed well.

\subsection{Sports Games Have Special Functions towards Physical Exercise}

Sports games are made up and created specially according to people's different age, gender, physiology, psychology, physical fitness and so on. Playing games according different physical difference (such as physical ability, technical ability) can help all the students to do physical exercise and build their bodies ${ }^{[3]}$.

As for university sports teaching nowadays, most universities adopt both forms of general sports lessons and specific elective lessons. General sports lessons are taken in freshman grade and specific elective lessons are taken in sophomore grade, with the goal of improving all kinds of physical fitness at the first year and making a good foundation for further specific elective lessons. As general sports lessons mainly involve track and field event, students feel boring in the studying process. If sports games can be well applied into it, students will be interested in track and field classes and strengthen their physical ability at the same time. For example, while teaching speed quality, it is possible to adapt and make up the relay and take more short-distance relay race, such as $20 \mathrm{~m}, 30 \mathrm{~m}$. During that progress of games, speed quality exercises can be improved and exercised; at the same time, it is better for teachers to control the class and do teaching.

\section{University Sports Teaching}

As for modern university sports teaching, based on the principle of taking students as service subjects and teachers as guidance, what is important for teachers is to teach only the essential and ensure plenty of practice, in order to stimulate students' subjective initiative and let them take part in sports exercises consciously. It breaks down previous unilateral actions and forms bilateral interactive way. Developing students' right view of life and value, is also one of the important ways of quality-oriented education. Major tasks of university sports teaching also involve cultivating mind and morality, besides improving physical fitness and strengthening body, which is also an important component of improving students' whole qualities.

\subsection{Functions of Sports Games in Different Parts of University Sports Teaching}

As an important part of university sports class, sports games run through the whole process of sports teaching, which has special functions to activate class atmosphere, arouse the enthusiasm and the initiative of the students and promote the formation of knowledge skills. Sports games can enable students to practice their bodies in a happy atmosphere, boost friendship and solidarity and cooperation spirit between students. In order to make students better grasp the activity skills and build up their bodies scientifically, there are three links during the teaching process of university sports process, i.e. preparation part, basic part and concluding part ${ }^{[4]}$. These three parts are closely linked and cannot be separated. Thus, during teaching process, to add some sports games can achieve better teaching effect and complete teaching tasks.

\subsection{Functions in Preparation Part}

Main part in preparation part is warming-up exercises, whose goal is to warm up bodies and organs of the students, help the nervous system reach certain degree of excitement and make better adjustment, in order to make their bodies at preparation state for working. In traditional teaching, warming-up exercises are boring 
which involves jogging, free-standing exercises and other links, which can working as warming-up functions. However, through several years' teaching practical cases, this form cannot adjust thinking excitability of the students better and students have to do exercises as the teachers' intentions. If we add some games in it appropriately, junctures can be extended and ligaments can be lifted, which is good for strengthening athletic ability of different organ systems, overcoming inertness of the body and making body keep at working status. At the same time, athletic ability can get close to the requirements for technical movement while training. Games can be corresponding with its content and requirement, which is helpful for teaching and practicing and works as auxiliary function. Like the game of "grouping after listening to the numbers." In that game, students can make new groups according to numbers, which can warm up their bodies, as well as adjust the excitability of their nervous centralis. Thus, if proper games are added into all parts, it can enrich and promote teaching measures and ways. Through games, students can be much easier to enter sports status and avoid hurting in the later activities, which make a good foundation for later basic part and play an important role in developing teaching content for teachers.

\subsection{Functions in the Basic Part}

During this part of teaching, teachers should stimulate initiatives in a better way, in order to let them take part in the sports activities willingly. Especially for new teaching content, as new content and action skills, students often come across different kinds of problems while studying, especially for the action skills. If the teacher can study teaching methods carefully and add some interesting games in a proper way, the teaching function can be clearly shown.

Basic part mainly involves reviewing what they learnt before, and then adding new teaching contents. During the reviewing and studying processes, methods and measures of games can be adopted. 2 to 3 games can be arranged and set for every new content and games shall be differentiated by its degrees of difficulties. Arrange the games form easy one to hard one. While studying new lessons, games with low difficulty can be used and games with big difficulty can be used at the reviewing part. Contents and forms of the games should also be distinguished, in order to enable students to have the feeling of freshness from beginning to end, and strengthen students' physical fitness of students as the increasing of difficulties. Choose different games according to different teaching content. Some of them pay more attention to improving physical quality of some aspects and mastering some skills. Some of them emphasize more on improving physical strength and intelligence. Some of them aim at enhancing psychological quality and moral character. And some of them make students know competition rules and their applications through the process of playing games. For example, while teaching basketball lessons, the teacher can develop students' control level by games of dribbling relay race and full-court dribbling and shooting; furthermore, these games can also improve students' speed, strength and harmony, and they are helpful to improve vital capacity and blood supply functions of heart.

\subsection{Functions in the Ending Part}

While doing coding-down exercises, games which help to reduce fatigue, promote recover of the physical function and relax physical and psychological parts, should be done. Finish and conclude in proper time. When time is up, activity times are completed, activity goals are reached, participates are not tired or are excited to play more, teachers should end the game and conclude carefully, so that students can collect experience and improve themselves by concluding gradually. First, evaluate game result fairly and comment on the performance of the participants in the activities. Teachers should point out advantages and disadvantages in following disciplines and rules, applying techniques and strategies, developing collective intelligence of both parties and clarify attentions for next activities. Main tasks of this part are to calm the students down to a relatively quiet status and relax muscles well; therefore, some relatively quiet and static games should be used, so that heart rate and breath of the students can become stable and their nervous excitation are lowered down and get recovered. This provides an important basis for scientific sports activities.

\section{Problems Needed Attentions for Applying Sports Games while Teaching}

The aim of putting sports games into sports teaching is to give full play to special functions of sports games. Start from its essential characteristics and values for teaching and help the completion of sports teaching tasks to improve teaching effect. Following problems shall be paid attentions to while teaching, in order to give full play to sports games:

\subsection{Safety and Health of Contents and Forms}

Although sports games are various, not all forms are suitable for teaching activities. In order to teach and get better results for teaching, sports games with pedagogical meaning and safe are in favor of completion of 
teaching tasks, develop right posture of the bodies, developing physical fitness and basic activity abilities of the students and improve physical fitness of the students. Before playing games, teachers should introduce the name, method, rules, requirements and attentions required in the game in a brief and right way. Choice of the games' content, times, density and arrangement of the amount of exercises should be correspondent to physical and mental characteristics of the game players. Make safety education for the game process by rules, requirements and attentions. Sports games which are meaningless have superstition in them and do harm for students' physical and psychological health should be prohibited. Besides, Sports games with complex actions which are against body health principles should be avoided. Through games and activities, encourage the participants to compete fairly and view success and failure in a right way. They should be brave to face the challenges and failures, give full play to abilities of their own, overcome difficulties and win with strong will and firm confidence, in order to improve mental adaptive capacity. At the same time, make more friends by taking part in sports games, so that students can experience happiness and interest brought by games and their minds and bodies can be satisfied well.

\subsection{Specialty and Science about Choice, Rules, Making up and Organization of the Content}

The aim of games is to complete teaching tasks more effectively. Thus, the content should be tightly related to the text and games should be created according to their textbook and actual situations of the students, in order to improve teaching quality in real sense. While making up the games, choices of games should be different according to the age, genders, physical qualities, skills and techniques of the students. For example, the difference of gender between boys and girls: girls generally like games with happy and elegant rhythm. However, boys like violent and rude games with strong rivalry. As a result, teachers should not only prepare some tasks to develop girls' physical qualities but also emphasizes on rhythm and movement. While making up the rules, students are allowed to carry our creative activities within the rule scope in order to guarantee smooth implementation of the games. In this way, potentials of students can be expressed. Teachers should teach students in accordance of their aptitude and update contents and rules of the game gradually, improve students' initiative in a better way, so that special goals of the game can be reached. At the same time, as for the organization of the games, teachers should consider the actual level of the students' bodies and treat students at different age or in different genders differently and organize games scientifically with the principles from the easier to the more advanced, from the shallower to the deeper step by step. Cautiously observe physical conditions of the students while playing games and control the activity quantity and activity dense better.

\subsection{Organization and Discipline Should Be Stressed while Playing Games}

Organization and discipline should be stressed while students are playing games, which is a guarantee to carry out games and reach teaching effect smoothly. Especially after grouping, every student should play the game as the designed way and rules. Particularly like the games of throwing, running and jumping and confrontation, orders and approaches should be paid more attentions. Otherwise, chaos would take place which increases safety hazard, even injury accident would happen, which affects teaching. While playing games, teacher should observe and control the temper changes of the students and teacher should make an example, which is very important. Teachers should care about students in a full way, especially for students with weak physical quality. Teachers should encourage them and let them know the warmth of collectivity. Thus, sports games must be well organized and arranged, and they should be lively and vivid in good order. And its functions can be exercised effectively by scientific and safe teaching.

\section{Conclusion}

Sports teaching is an important component of teaching activity and is also one of the important factors to improve quality-oriented education all around. Sports games can enrich contents of sports teaching, stimulate students' awareness and initiative of exercises, which make traditional teaching happy teaching and change one-way teaching mode between teachers and students into bilateral activity between teachers teaching and students learning. Therefore, select some games, which are arranged reasonably according to actual situations of the students, and apply them into university sports teaching, after understanding real features and functions correctly. In this way, it will not only activate class atmosphere well, but also improve teaching quality, embody teachers' standards, boost students' physical quality, cultivate students; life-long sports awareness and develop individual psychology to a healthy direction. In the rapid development society, integrate sports games into university sports teaching and serve sports teaching organically, can enable sports teaching to be a real teaching process, so that it lays a solid foundation for cultivating high-quality talents and enhancing results of quality-oriented education. 


\section{References}

Cai, B. C. (2002, April). Comparison between Healthy Sports Teaching and Traditional Sports Teaching. Liaoning Sport Science and Technology, 4(2), 62-63.

Chen, L. J. (2005). Sports Games Application in Sports Teaching. China Science and Technology Information, 12 , 71-83.

Gao, K. (2003, June). On Sports Game Teaching. Journal of Dandong Teachers College, 25(3) 121-122.

Qu, Z. H., \& Yang, W. X. (1999). New Horizon of after School Sports. Kunming Yunnan Press.

Ya, S., Zhao, M., \& Li, H. J. (2000). Sports Games - Major Forms and Measures for National Fitness. Journal of Physical Education, (1) 66-68.

\section{Copyrights}

Copyright for this article is retained by the author(s), with first publication rights granted to the journal.

This is an open-access article distributed under the terms and conditions of the Creative Commons Attribution license (http://creativecommons.org/licenses/by/3.0/). 